\title{
Structuration, ICTs, and Community Work
}

\author{
Larry Stillman \\ Monash University $<$ larrys01@optusnet.com.au $>$ \\ Randy Stoecker \\ University of Toledo $<\underline{\text { RSTOECK@UTNet.UToledo.Edu }}>$
}

\begin{abstract}
This paper reports on a project which was undertaken with a network of Neighbourhood Houses (community-based organisations) in the Western Region of Melbourne, Australia. The region is an area of high social-economic need, and at the same time, contains a major growth corridor. A decline in investments in communitylevel ICT systems is producing technical and informational gaps impacting the work of Neighbourhood Houses, and illustrating how funding cuts impact sustainability. The researchers employed a community-based research process, drawing on the perspective of structuration theory, to identify and diagnose the sustainability issues. Through a survey, interviews and focus groups, we identified six areas of ICT of concern from sustainability perspective: computer troubleshooting, quality technology support, resource directories, web page development, communication costs, and relationships with local councils. We are now working with Neighbourhood House coordinators on the action phase of the project to fill those identified needs.
\end{abstract}

\section{Introduction}

From the mid-1990s to 2004 the State government of Victoria (supported by politicians across the political spectrum) invested as much as $\$ 50$ million Australian dollars to support community-focussed ICT infrastructure. VICNET (Victoria's network, www.vicnet.net.au), was supported as a flagship in this process, providing training, support and connectivity to community organisations across the state. Other funding went directly into providing hardware and software for public libraries and community organisations.

The vision behind much of this expenditure was that paying for hardware and software start-up costs, and providing time-limited basic training and technical support, would create a community ICT infrastructure and community-level skill set that would then be self-sustaining. So, by 2004, state funding had been significantly reduced, with VICNET being downsized and other funding initiatives concluded.

We are already seeing, however, that this was not a sustainable model for community IT infrastructure. At the community organisation level, old hardware is beginning to fail, software is out of date, and staff turnover has reduced the IT skill base. It was clear that the original approach of 'start-up' funds to kick-start a community technology infrastructure without long-term investment by the state was not sustainable. In addition, the opportunities for ICTs to enhance the work of community organisations through developing and using custom-designed databases, has increased as the hardware and software have become more sophisticated. So decreased funding means that not only existing capacity declines, but additionally that new capacity cannot be realized. 
The project reported in this paper set out to diagnose the ICT gaps surfacing from this unsustainable community ICT funding model within one sector of the community work 'industry'-Neighbourhood Houses - in the western suburbs of Melbourne, Australia. The Western suburbs or region of Melbourne covers about one-third of the metropolitan area of the city, including seven local government districts with a regional population of 650,000 , spread across $1,330 \mathrm{~km} 2$ or 5132 miles. The region is much poorer than the rest of Melbourne, including an old industrial heartland and working class suburbs. More recently, pockets of middle-class affluence have developed, in both older 'gentrified' inner suburbs, and in particular designated growth corridors. The region also includes market gardens, and on its fringes, is rural in character. There is poor public transport infrastructure in many areas, and the Western region is at the high end of every statistical index of social disadvantage (eg. unemployment, failure to complete school and poverty). The city of Brimbank is the area with the highest number of new immigrants in the State, and Melton, on the metropolitan outskirts, is the fastest growing city in the state (Department of Human Services (Victoria) 2002). The region is served by 34 Neighbourhood Houses, and they were the focus of this project.

This paper reports on a community-based research process, informed by structuration theory, to involve Neighbourhood House coordinators in developing plans for a more sustainable community IT infrastructure. We are already beginning to see the results of the work in government representatives showing renewed interest in funding ICT.

\section{Structuration, ICTs, and Community Work}

As researchers, we approached the question of assessing the sustainability gaps of community ICT funding from the perspective of structuration theory. Structuration theory is frequently associated with the work of Anthony Giddens (1984; 1987), though other researchers have adapted it to study the use of information and communication technologies (Orlikowski 1992; Rose 1999; Orlikowski 2000). Such a perspective combines an interest in how social structures divide or restrict individuals and collectives with an interest in how human actors come to redefine situations so that they can confront or overcome the challenges created by social structure.

Axiomatic to structuration theory is the principle that the 'structures' of everyday life and institutional life are reproduced on a daily basis through the interaction of human agency, institutionalized rules, and the distribution of material resources. Giddens says:

In structuration theory 'structure' is regarded as rules and resources recursively implicated in social reproduction; institutionalized features of social systems have structural properties in the sense that relationships are stabilized across time and space. 'Structure' can be conceptualized abstractly as two aspects of rules -- normative elements and codes of signification. Resources are also of two kinds: authoritative resources, which derive from the co-ordination of the activity of human agents, and allocative resources, which stem from control of material products or of aspects of the material world. (Giddens, 1984: 31)

Social structure, then, is both in people's heads in the form of stable, institutionalized rules, and "out there" in the form of material resources. Ongoing, micro-level interactions or social conventions, including use of power and resources result in what are called 'structural principles', which over time become the recognisable properties or characteristics of social systems such as community networks (Giddens, 1981: 170).

For the student of ICTs, of particular interest is the creation and reproduction of 'technologies in practice' - the actual, ongoing process of the creation, distribution, and reproduction of people's understandings, interactions and uses of artefacts. ICTs are one example of such artefacts and have the potential to extend, expand, and contract time and/or to create different forms of space (e.g. the 'virtual office', 'home-based work'), and store personal and institutional memory in different ways than were previously possible (Hagerstrand 1970; Giddens 1984; Giddens 1987; Harvey 1989; Adams 1995). However, technologies are not inert objects: Actor Network Theory provides the insight that technologies in fact, appear to have their own agency with which humans interact (Latour 1994). For example, email can be seen to 'run' a person's life, when in fact, of course, people have the agency to turn the machine 
off, rather than the other way around. In this we see that both material reality, and people's definitions of that reality, are important to understand.

The application of structuration theory to a community ICT context, particularly in relation to nonprofit organizations, is challenging. Structuration theory has generally focused upon the contrasting constructions of technology held by managers of for-profit businesses, particularly large corporations, though Orlikowski suggested that her framework for 'enacted technology' should be applied to the study of non-corporate settings (Orlikowski 1992; Orlikowski 2000). But how should that be done?

In the community ICT context, a number of developments within the broad field of structuration theory are helpful. Adaptive structuration theory focuses on 'the relative balance in the deterministic influences and wilful choices' in small group settings (Poole 1986) and suggests possibilities for how members may exercise more influence than they otherwise think themselves capable. However, while De Sanctis and Poole (1994), emphasize the importance of local social structures in underlying the particular character of, and contingent relationships to technology in institutional settings, for the purposes of this paper, we wish to emphasize the continuing importance of access to resources as real structuring forces in determining technological use. Without sufficient basic resourcing, the capacity of Neighbourhood Houses to engage in dynamic agency through using their particular value sets to affect community change through use of technology in liminal spaces is severely constrained. In fact, we can suggest that the structural contradiction between the normative value set of community development (as expressed by the collectivist approach of Neighbourhood Houses), and access to facilitative resources is one of the most common reasons for the difficulties in developing project or initiative sustainability. Our paper is directed to identifying the factors which contribute to this dichotomy. 1

Furthermore, because Neighbourhood Houses are often women-centered environments, a feminist perspective on 'situated technologies' located in particular gendered constructs of home and work (Harraway, 2000; Orlikowski 1992, 1999, 2000, 2002; Latour 1994) is helpful. In our particular case, ICT use is occurring in the context of neighbourhood organizations as 'liminal spaces' where the nurturing and caring culture associated with the private sphere of the family intersects with the harder world of the public sphere relationships in civil society (Dear, 2000, Turner, 1974, Zukin, 1991). Liminality is an important concept for structuration theory, as liminal social spaces are where social structures and independent action collide and produce social innovations. Community-based organizations such as Neighbourhood Houses focus that liminality - as they confront the private sphere issues and attempt interventions that require either public sphere resources or policy changes that are often at odds with existing social structures.

The question for us is how do ICTs operate in such focused liminal spaces and how do community workers use them as agents creating structural change rather than be subject to them as constraints on change? In what are now being called 'technologies of care', there is a call for a 'unified and coherent' perspective of how the deployment of ICTs are to occur in welfare services (Gould 2003). This is important, since the relationship between those providing community services and the technologies they use is strained by increasing expectations of 'rationalised' and efficient forms of service, which are regarded as having 'colonised' the 'new technologies of social and welfare care' (Webb 2003: 226).

Community ICTs today are therefore more than a 'black box' for which levers are simply pulled and outputs occur by 'dumb terminal' human agents. Technology is equivocal and contingent, and its use is characterised by 'chronic surprise', for which constant adaptation and response is necessary (Weick 1990). ICTs, as a particular form of technology, have become a central tool in Neighbourhood House work, evidenced by the fact that the lack of sustainability of the Victorian State government funding model is now creating problems for the Neighbourhood Houses, as we will show.

\section{Methods: Assessing ICT Sustainability Gaps}

A criticism of structuration theory is that it is often little more than a heuristic device, perhaps providing some illumination of the interaction of structure and agency in particular situations, but providing no lessons for how to build better social structures, or deploy more effective agency (Gregson, 1989). Perhaps one reason for that criticism is that structuration theory has not been linked to methodologies that can lead to practical results. In our case, the heuristic quality of structuration theory, which suggests broad 
categories rather than specific indicators of both structure and agency, is useful in allowing room for agent participation in making the research process as practical and relevant as possible.

Early on in the process we decided to use an action research model called community-based research (CBR) (Strand et al. 2003). CBR sees research as a collaboration between researchers, who have access to abstract knowledge, and community members, who have expertise in the experience of their own communities. These two forms of knowledge complement each other, merging expertise in community characteristics with information from outside of it (Nyden 1997). The researcher, working in a partnership, becomes an amplifier of the people's 'voice'. From a structuration perspective, Giddens has referred to this as the double hermeneutic--the change brought about through agency on the researcher and the researched. In later writings, he characterised this two-way interaction as in fact a characteristic of modernity, with the modern citizen engaged in constant reflection and reinvention in life practice. Research systematizes that process. (Giddens, 1984 ; Giddens 1990; Giddens 1991; Giddens 1992).

Because CBR emphasizes researcher-community collaboration, it deeply respects a variety of knowledge forms. Community stories are as important as statistical research. What people think, know, and say is valued in their own terms as their 'definition of the situation'(Berger and Luckmann 1966; Guba and Lincoln 1981) and combined with other forms of knowledge. Here, again, is where CBR uses structuration theory, deploying research as a way to make explicit the actors' definitions, and combining it with information from the actor's structural context, so that they may act more consciously and strategically. In this case we were able to bring information from our knowledge of community ICT practices generally, and resources of the Melbourne metropolitan area, to combine with Neighbourhood House coordinators' identification of issues and problems in deploying ICTs in their work.

Another aim of CBR is to create social change through empowerment (Strand et al., 2003; Fetterman 1994). CBR has a specific agenda of social engagement. Research designed for social change differs in significant ways from basic research. Community participants play a much stronger role in every step of the research process from choosing the research question, through designing the methods, collecting the data, conducting the analysis, and reporting the results. Most important to the practice of CBR is ownership of the research process by the people who will ultimately be impacted by it. If community members don't feel a sense of authenticity that is connected to their needs, they will not participate and they will not use the research. It was crucial to us that Neighbourhood House coordinators be involved in defining their ICT needs and action steps for meeting those needs so that the project would not stall after the report writing stage.

For this project, as researchers, we brought to the table a broad concern about the sustainability gaps in use of information technology in community-based organisations. We encouraged the Neighbourhood House coordinators to shape the research questions within that context. In this sense, we as researchers were following an 'initiator' model of CBR where the researchers bring the project to the community rather than vice versa. Such a model is particularly difficult to implement. First, it requires the researchers to have exceptional community organizing skills and to devote extra time to organizing meetings and recruiting participants. Second, it requires shifting the initiation energy from the researchers to the community participants as early as possible in the process. If the researchers remain the initiators, the likelihood that the research will have practical consequences will be greatly reduced.

\section{Process: Assessing ICT Sustainability Gaps}

The project is the outcome of many years of discussion between Community West's director at that time, Mark Samuel-King and Larry Stillman about the difficulties which many small community organisations appeared to have in making effective use of ICTs. Community West is a major social services agency in the region. Randy Stoecker while based in the USA, had visited Australia on a number of occasions in the past, and was well aware of the information and technology needs of community-based organisations in the Melbourne area.

Research funds were awarded by Monash University' Faculty of Information Technology, with additional support from Community West, Inc, to conduct a form of participatory formative evaluation concerning the information and technology needs of a network of community agencies in the Western 
Suburbs of Melbourne. Planning for the project took place in the last part of 2003 and first half of 2004, with actual field work in the first half of June, 2004.

\section{Preparing for the project}

Early meetings were held with a number of Neighbourhood House coordinators and a representative of local government in early 2004 to explore general issues of ICT usage in Neighbourhood Houses and our methodologies. One meeting included the second author on speakerphone. Another planned speakerphone meeting was disrupted by hardware problems 2 . These preliminary meetings suggested that exploration of the following issues were of interest during the research process:

- how ICTs are used in the everyday work of Neighbourhood House coordinators;

- the technical skills base of Neighbourhood House staff and volunteers

- the issues Neighbourhood Houses face in both information management and technical management;

- the place of Network West and its website in supporting Neighbourhood Houses in addressing information and technical management issues.

As we worked with the Neighbourhood House coordinators, a set of research methods emerged that included document review, a survey, in-depth interviews, a focus group, and a planning group.

\section{Conducting background research through document review}

To get a sense of the potential scope of ICT sustainability issues among Neighbourhood Houses, we reviewed a variety of documents about Neighbourhood House programs, some recommended through discussion with Neighbourhood House coordinators. These included in-house documentation from the Association of Neighbourhood Houses and Learning Centres, state government documentation, and a number of academic studies of Neighbourhood Houses, including a study by post-graduate students at Monash University in the mid-1990s (Dillon 1995), and a PhD thesis by Melissa Permezel (2001).

\section{Surveying Neighbourhood Houses}

The next step was to develop a survey to both announce the project to a broader group of Neighbourhood Houses and to gather initial assessment data on the issues they were facing in deploying ICTs in their work. In our survey design, we sought to adapt and modify a number of surveys which had been used with Neighbourhood Houses and like organisations. These included: the IT survey of Neighbourhood Houses conducted by Duke Street in 1999 for ANHLC; earlier surveys of IT use, used with Neighbourhood-based organisations in the area; and Beverley Koerin's survey of neighbourhood organisations (Settlement Houses) in the US (Koerin 2003).

During April and May 2004, drafts of the survey were discussed at planning committee meetings and shown to colleagues and Neighbourhood House coordinators for comment. The researchers were mindful of the limited time available to coordinators to fill in surveys, and therefore a double-sided survey was developed which was accompanied by a stamped return envelope. These were sent out at the start of June with a one week return time, hoping to encourage immediate activity by coordinators. It was decided to use traditional mail methods rather than electronic means on the advice of the committee, in the belief that this might elicit a stronger response.

Of the 34 surveys sent out, 12 were returned. (a return rate of about a third being not uncommon in this type of research). It was also understood that a number of other unrelated surveys were distributed at the same time, which might account for 'forms fatigue'.

\section{Changing the process}

The survey, along with two intensive workshop meetings, were to be used for recruiting participants into the action phases of the project. However, an initial low response rate to the survey and lack of interest and time to take part in the planned workshops led to a quick revisiting of the overall research trajectory. After consultation with some Neighbourhood House coordinators, the overall research protocol was revised. First, rather than asking coordinators to attend two all-day workshops, the offer was made to conduct briefer 60 minute site visits/interviews at a representative group of Neighbourhood Houses who could not attend the workshop meetings. A two-hour focus group was also conducted with a group of Neighbourhood House coordinators who had indicated some interest in the initial workshop. This process 
was then followed with a two-hour planning meeting one week later, focusing on the most common issues raised through the site visit interviews and focus group.

Significantly, once these changes were made, there began to be a greater involvement from the coordinators and they offered more direction on how to structure the project for the greatest benefit. They emphasized:

- having the opportunity to review and revise a draft of the report;

- producing a set of funding proposals resulting from the research;

- organising a public launch event to present the research recommendations.

Their advice is being implemented in the subsequent stages of this project.

\section{Interviews}

On-site interviews of one hour each were conducted with coordinators at seven Neighbourhood Houses, attempting to include both the close-in suburbs and more remote locations, recruiting participants by phone. Extensive notes were taken, including verbatim quotes. One author also conducted one phone interview, for a total of eight. When added to the five participants of the focus group, qualitative information was received from thirteen Neighbourhood House coordinators. There was a partial overlap of interview and focus group participants with survey respondents, resulting in some form of information from more than half of the Neighbourhood Houses.

An open-ended interview format was used focusing on the following questions:

- What are the major activities of your Neighbourhood House?

- How do you use information in those activities (in classes, referrals) and how complete is the information?

- How do you use information technology in the Neighbourhood House and what issues do you face in using information technology?

The results of these interviews began to shape some of the issues that were brought to the planning meeting.

\section{Focus group}

As mentioned above, after hearing concerns from Neighbourhood House coordinators, the initial strategy shifted from two all-day workshops to site interviews and briefer focus group and planning group meetings. Participants were recruited by e-mail and phone call follow-ups, and as with the interviews, extensive notes of what was said by participants were taken.

The initial focus group was scheduled in one of the western suburbs and was attended by representatives of five Neighbourhood Houses. The focus group was organized around the same topics as for the site interviews to maintain as much consistency as possible in the information obtained. As a consequence of this, it was possible to observe a set of themes emerging across the thirteen total participants (from both the site interviews and the focus group), which are described below. At this meeting, participants also made initial suggestions for how to move from the research phase to action, with a suggestion for a public launch of the research report with invitations to government officials.

\section{Initial Analysis}

Often in community-based research, the researchers will frequently conduct an initial analysis of the data, usually for the purpose of informing a deeper, more participatory analysis and planning process. Usually, at this stage, the analysis consists of organizing the data into issue categories. In this case, the survey, interviews, and focus group data seemed to suggest six categories: computer troubleshooting, quality technology support, resource directories, web page development, communication costs, and relationships with local councils. The data was organized into these six categories, and the information was brought to a two-hour planning group meeting, which was to meet one week after the initial focus group.

\section{Planning group}

Participants were recruited to the planning group meeting by e-mail announcement and phone calls. Representatives from six Neighbourhood Houses, and one funder, attended the meeting. 
The six themes were ranked in order of importance, with computer troubleshooting, quality IT support, and resource directories receiving substantially higher rankings. Twenty to twenty-five minutes were then spent on each of these themes, identifying a goal the group wanted to accomplish, the strategies needed to pursue the goal, the players who needed to be involved in each strategy, and the resources required. The remaining time was divided into approximately fifteen minute segments to address each of the lesserranked issues.

\section{Reporting and Action Steps}

Within a few weeks of the planning meeting a draft research report was available and returned to the coordinators for comment. Extensive comments were not received from the coordinators. Instead, the researchers began to hear from Neighbourhood Houses that they were already using the information in grant applications, and requests began to be received from Neighbourhood Houses in other regions for copies of the report, and it made its way into the hands of government ministers. A further discussion of the outcomes to date is included in the conclusion section.

\section{Issues in Sustainability of Community ICT}

Returning to the insights of structuration theory, each of these six issues-- computer troubleshooting, quality technology support, resource directories, web page development, communication costs, and relationships with local councils - has both structural and agency components. In some cases the structural aspects of the issue require few resources or political intervention to overcome, creating plenty of room for agency to have an impact. In other cases the structural issues are more prominent, and will require more sophisticated strategies on the agency side of structuration theory.

\section{Computer training $\&$ troubleshooting}

One of the main sustainability issues faced by Neighbourhood Houses in the face of government funding reductions is to have functioning hardware and software. On the structural side of the issue is the fact that ageing computers are more subject to breakdowns, require more tweaking to handle new software, new web applications, and bulky formatted e-mail. In addition, piecing together potentially incompatible hardware and software components produces increasing errors. The provision of cobbled-together and aging computers available to neighbourhood residents who may inadvertently change settings, download dangerous software, or introduce viruses, creates even more problems.

On the agency side of the issue is that at least some of the problems experienced by such hardware and software configurations are relatively easy to fix. However, many of the Neighbourhood House staff either lack the skills or the confidence to make basic hardware repairs or software reconfigurations. Of the Neighbourhood Houses interviewed, only three have such a combination of skills and confidence, with more than one staff person who can do their own computer troubleshooting. The other Neighbourhood Houses rely on volunteers or paid IT support. Additionally and in some cases, relying on a single individual can have drawbacks:

I should be much more up to speed [on computers]. I have the ICDL International Computer Driver's License]. Everything I do I'm self-taught. Having an IT guy has lulled me.

One of the consequences of being 'lulled' is that many Neighbourhood Houses often wait days or even weeks to fix even relatively simple problems. The survey found that only two Neighbourhood Houses waited less than a day for computer help, two waited one to two days, and five waited more than 2 days. In the site visits and focus group it was learned that one coordinator had been without e-mail for weeks. Another had only one of two public Internet computers able to access the Internet. Yet another coordinator had been unable to access the Internet for weeks with her centre's only Internet-enabled computer.

An example of basic troubleshooting which came up during one session -- and for which the researchers were asked on-the-spot advice -- was how to uninstall and reinstall a mouse which did not appear to be working. Another example which was raised by several people was how to use the Control Panel settings more effectively. Another area included 'preventative maintenance': how to do backups, cleanups, upgrades, installations, and defrag the hard drive.

The coordinators recognize the need for some further training in basic troubleshooting. 
A general troubleshooting course would be good. It needs to be recognized or accredited. Something equivalent to the ICDL [International Computer Driving Licence]. Don't have it as an obligation of a funding body. If there were a set of guidelines for basic skills--things like terms--and what to do for a computer that can't access the Internet. I don't know what to do beyond the basics.

There should be some courses for dummies like on the insides of computers and troubleshooting.

One of the structural barriers to providing such training, of course, is the lack of time available to other Neighbourhood House staff who are often casual or hourly employees. And coordinators, who are often part-time themselves, are often running at full steam just trying to keep everything running smoothly.

Working part-time makes it hard to schedule things [like trainings]. Even if it was one to one, people would already be committed to teaching a class or something.

The way we work is fragmented.

I have other jobs.

It's great to have the training, but it's about priorities at any time.

Coordinators understand the dual dilemma of lacking both time and technical skills. The survey showed that time and technical skills seem to be the most important problems facing people in using computers. And they lack the person resources to build IT maintenance into their workloads:

Even issues like ordering a cartridge--you go to the cupboard and it's not there. Or the website domain is running out and who will do it? We argue about whose responsibility it is. I got really angry and said, 'this isn't my job'.

There are many training needs beyond basic troubleshooting. But training in troubleshooting emerged as an important entrance training program that could actually save coordinators significant time and money in the long run.

\section{Good IT support}

The other consequence of the structural lack of ICT funding is that the problems caused by aging and cobbled-together computers that are beyond the help of basic trouble-shooting then require advanced IT support for which there are also structural barriers to funding. The survey showed that there are over 170 computers (PCs and laptops) across the 12 Houses, ranging from a single PC to $30+$ in at least 3 Houses. Most computers are less than 3 years old, though about a quarter are at least 5 years old. If the same pattern holds true for the other 22 Neighbourhood Houses, there are approximately 500 computers among the Neighbourhood Houses in this area needing effective maintenance.

The least resourced Neighbourhood Houses are in some ways at the most risk of failing due to lack of decent IT support. When their one computer goes down, it cuts them off entirely from the flow of information across the third sector:

It's hard to get a response from e-mails at smaller Neighbourhood Houses.

The need for good IT support has intensified recently due to several factors. The first is a consequence of ageing hardware.

I bought a new computer, but it doesn't have enough RAM - 4 or 5 years old [and there] is not enough capacity. You've got to be on your own game, it sounds like a corporation, but this is one of the busiest places in [the area]....people don't believe this. It's full on, community education, development.

The survey shows that at least a quarter of the PCs are at least 5 years old, and many are therefore inadequate for current technological demands. Access is roughly evenly split between narrowband (phone line modem) service and broadband.

Good equipment is expensive in the short term, but reduces the need to expend coordinator time on trouble shooting, downtime, or paying for maintenance services. Neighbourhood Houses, like small 
business, either need the funds to regularly update their hardware and software, or need to have the knowledge to choose the right equipment when attempting to achieve cost savings through the acquisition of recycled machinery.

My problem is [that] the technology is crap. There is no money for good technology.

Even those Neighbourhood Houses that have decent on-site support lack adequate hardware:

We have an IT department. But IT stuff is hugely expensive. But the location I'm in, we've only got one computer linked to the Internet. So we have to share it.

The world of computing is also becoming more complex and fraught with more challenges than at any time in the past. The need to update operating systems, particularly for machines running vulnerable Microsoft operating systems, anti-virus software, firewalls, and other things requires increasing expertise and attention.

We're getting viruses all the time. We have a computer maintenance book that logs what happened and what action was taken.

The major challenge [with computers] is keeping things up to date.

We struggle with keeping our system up to data and finding stuff. People have to understand they aren't working at a TAFE [College of Technical and Further Education].

Those Houses that maintain computer labs for their English as a Second Language (ESL) students also face challenges as the ESL software becomes more complex, memory hungry, and difficult to access over the Internet. These comments come from a number of coordinators:

The ESL students sometimes can get in and change the settings because they don't know what they're doing.

Laptops came with a wireless hub and router, but it wasn't set up right so we bought our own wireless hub and set it up.

We use a server to duplicate some of the sites on the Internet so all the laptops don't have to go through a single dial-up connection. The ESL sites also have a lot of advertising, which wastes bandwidth.

Another factor intensifying the need for computer support is the decline of VICNET, which had provided free support in the past through its outreach programs such as Skillsnet or MC2. But such support has become increasingly limited and uncertain.

Even when there is technical support available, it often does not fit the needs of the Neighbourhood Houses: Coordinators do not like hearing incomprehensible IT jargon from technicians who are not attuned to the particular needs of Neighbourhood Houses.

Only one of the Internet access points is working. Skilled IT people are incredibly hard to source. There are a lot of charlatans out there. They talk in doublespeak. Or they have worked in banks and they are trying to force layers of security.

Our tech support guy says we can transfer files across computers but he hasn't shown us how. That would be particularly useful with e-mail where we need to send things to each other.

What we need is good networks inside our own units. But I have to physically cart stuff down to my computer.

We have through the cluster, money. One of their priorities is tech support. Getting that person to come is not that easy. If we come in Friday morning and can't log onto the internet we can't do anything about it before we start class. We have one computer dying now and it is affecting the entire network.

With a lack of IT support that understands Neighbourhood House culture and needs, as noted by this Neighbourhood House worker, the technology can induce chaos. 
You're really on your own. I e-mail everything home. But sometimes I forget. So now I use a memory stick. I have information all over the place. I haven't had e-mail for six weeks.

On the agency side of the issue, and because Neighbourhood House coordinators lack basic troubleshooting capacity, they are more dependent than necessary on expensive and not always timely IT support. Systems are down, information is lost, and the frustration level of workers and clients who may be learning IT skills is high.

I've talked with three coordinators whose computers have gone down and they've lost everything.

A number of Neighbourhood Houses rely on volunteers for IT support, and are happy with the results:

You hear stories about other Neighbourhood Houses where the computers are in trouble. It's pretty good here. Two people work on computer maintenance. We have a young man who helps who has been coming in for years and years.

We've got a volunteer. He maintains things along with L----. He has a relationship with a computer company.

But when those volunteers move on, they can be difficult to replace. And dependence on one on-site expert can introduce real vulnerability.

What would happen without the computer guy on site? We'd be $\mathrm{f}^{* * * *} \mathrm{~d}$.

And that one expert may not be enough to begin with.

We wish we could have tech support five days per week, and have our open access computers open at night.

ESL uses the computers four times a week. Sometimes people walk in and say 'can I use the internet?' We need volunteers who can be here when that happens so we don't have to keep running back and forth. We have one man who volunteers after having taken a computer class in Richmond and then he moved here.

[On- site tech person speaking] I need more time to learn stuff like moodle.org, the learning center software. I'm here 14 hours a week. Plus I do some stuff at home. I pretty much am able to do the troubleshooting. But there is not time to create non-admin accounts for students on the laptops, which would be a pain anyway because then you have to log out and log back in to install things. I also want to reconsider the VICNET dial-up. It gets pretty expensive redialing because of all the dropped connections.

\section{Managing Information Through Resource Directories and Databases}

Along with hardware and software, one of the main issues that Neighbourhood Houses face is information access and management. To a large extent, Neighbourhood Houses deal in information: through ESL and the wide variety of craft and skills courses, and referral activities. All of this relies on having access to well-organized information repositories. It is striking how well the Neighbourhood Houses do at managing information with such miniscule resources. But, as might be expected, Neighbourhood House coordinators cite a wide variety of information management needs, particularly in having access to directories and databases.

This issue operates at many different levels. Neighbourhood Houses engage in complex information activities, including the resource-intensive production of program flyers every term; databasing of all sorts: local tutors and students and the production and maintenance of different sorts of service directories; and the provision or access to information services (e.g. government benefit data and forms) for personal client work.

On the structural side of this issue is the need for access to people with advanced skills who can develop, maintain, and troubleshoot database software. Some Neighbourhood Houses have turned to developing their own databases to manage this information.

We have an Access database from our former assistant manager who was very system-oriented. It is great in that we manage information much better. We employed a consultant to help us put 
it together. It streamlines information. You are just overloaded with paper, and it is difficult to refer efficiently. We used to have hundreds of Word documents. It's lifted our game and has given us a tool to manage information.

The maintenance side of the database I haven't really thought about. Others can do that. There are hundreds of organisations out there that move or are closed.

In needs analysis we found [neighbourhood residents] said yes to computers, but then people wouldn't show. With asset mapping we found safety was a big issue. We also get contact details of people who are interested in things and then we can create a directory of things people want.

In all of these cited cases, however, there is no strategy in place for maintaining and updating the database information and thus for the need for Neighbourhood House workers to develop new skills and find extra time.

Solving the structural issues of access to expert database development and maintenance resources could dramatically expand the agency of Neighbourhood Houses. Among the resources that Neighbourhood House coordinators would find useful would be a directory of tutors, and many comments were made about the need for directories:

Some of our tutors aren't on-line, which makes it very hard to get in touch with them.

We use sessional staff and so if I need someone for a program I'll ring another House for a person.

I need a list of people [tutors] on an emergency basis.

When I did assets assessment I must have had 30 people who wanted sewing. I finally got the sewing tutor [after a lot of phone calls].

My yoga teacher would love to have more teaching available.

Coordinators also expressed some interest in having a directory of the courses offered by all the NHs so they could refer prospective students to each other.

If we don't do something we refer them to another Neighbourhood House.

Sometimes we can't find a tutor.

People ring here and ask where to get courses. We need a database of all the programs. If you put together all the organisations in Victoria you would know everything going on.

It is possible to consider such a directory. In Hobson's Bay, with the support of the local council, the Neighbourhood Houses have got together and created their own joint directory of courses.

Some of the Neighbourhood Houses have also begun thinking about developing databases of local residents so they can contact them about courses that may interest them, or services that they may not know about. In contrast to the tutor directory, however, coordinators would want to maintain local resident directories themselves to protect resident privacy.

A learner directory would be pertaining just to your House. A teacher directory would be across Neighbourhood Houses.

We would store the local directory ourselves. We wouldn't want that stored elsewhere.

These examples reinforce those versions of structuration theory that emphasize how changing situational definitions can impact ICT use as much as resource availability. An even more powerful example of the role that situational definitions play in the use of ICTs is in the perceived lack of referral directories among many of the NH coordinators. There are at least two regularly updated directories of services across the region that some Neighbourhood Houses use. It was surprising, however, how many other Neighbourhood House coordinators did not know of the existence of these directories. In some cases they learned of major referral organisations only by accident: 
We heard about Centrelink from students coming in with forms and then ringing them to get questions answered. Learning who to call in Centrelink was an education in itself.

One of the directories is database-driven and searchable online, by topic and by region, making the task of finding referral agencies dramatically more efficient. But at least some of the Neighbourhood Houses were more interested in a paper directory, or an online directory that looked more like a paper directory. The lack of positive definitions of a database-driven directory made it seem like a less-desirable alternative.

\section{Web Development and Management}

All survey respondents said they had a website. Yet, many of them are not sure why they should have a website, and nearly all lack the capacity to maintain one. At the same time, many of the Neighbourhood Houses also have a difficult time getting information from Houses in other clusters, and have a hard time getting information out about themselves. Aside from general funding, publicity is one of the recurrent issues facing the Houses. Exhibiting their own sophisticated understanding of the structural side of structuration theory however, the coordinators understand that their main challenge is reaching local residents, for which a website is still mostly not appropriate, as too many local residents lack computers and Internet access. Consequently, for local publicity, most Neighbourhood Houses rely on letterboxing.

We send out flyers four times a year, programs and courses, a lot on...40 or 50 things...so it does not cost a fortune to print, this is how it has to be done on one sheet. It goes out to 11,000 Houses with a walking company. It has to be at the printer next Tuesday.

Publicity is work for all of us, all use brochures, though newsletters, flyers, but I think $99 \%$ of those who use my House don't use computers...we don't use the Net to find out what's going on.

[We send out] six-monthly brochures to 6000 Households for the 3 centres. 3 or 4 local papers give free ads, as well as flyers. Most are in English, some are in multiple languages.

We have a frustration in how to market ourselves, first to people in the estate, but also to all of [the local area].

It takes a lot of time to get the word out. We still have people who don't know what we do. We do 8,000 brochures quarterly, drop-offs at centres, newspapers. We probably spend $\$ 10,000$ a year in advertising costs. There is no one thing that works. The brochure is probably the most important thing. But we are getting more email requests from people in the area.

When there is a desire for a website, the coordinators differentiated between websites for marketing purposes to government departments, what might be called an 'electronic brochure' with contact and program information, and a website for clients. The website for clients was seen as a much lower priority, since most contact is person-to-person. But at least one Neighbourhood House has created an intranet website for clients to access learning resources without having to wait for pages to download through the House's single shared dial-up connection.

We have a web site, mostly with links to other places. It's not official, it's just for students to use. We could create a more public site as a kind of brochure site. A lot of people who come here wouldn't have good Internet access. Other service providers would be high on the list of those having access.

In the individual meetings with coordinators and in the group meetings it was seen that there was a structural barrier inhibiting the technical skills required to build a website or provide email access to staff and students, based on the lack of time that staff and even volunteers could afford to both develop the skills and then spend time on website maintenance.

It's vulnerable because we're part-time workers and our employers are a committee of management. We end up with the roles on our lap. Our website worker has left, and now our website needs updating. 
I'm not internet proficient. I do that work at home. I don't have open internet at work - Council only has certain points available. I don't use the public access point in the Centre as people ask me questions. Council has a contract for a limited number of access points for internet access.

We have a website but have relocated to much larger premises. We haven't had time to maintain it. We had a volunteer to maintain the website but she went overseas.

\section{Communication Costs}

One of the things the researchers did not expect to find in this research was a widespread concern about the costs, in terms of time, ink, and paper, of using information technology, (perhaps because of structural imbalances between government (and university) departments that are relatively well supplied with advanced technology, and community organisations). In an age when everyone e-mails all kinds of things to everyone, one rarely stops to think what it takes to download and print out the oft-circulated and massive PDF files, pictures, and over-formatted word-processing documents. The Neighbourhood House coordinators, however, are concerned about these issues.

I would use ink and paper and time to print out attachments.

You have to print out hard copy forms for yourself.

With a recent health proposal, you had to print it out. You couldn't type it on-line.

Where we are you have to login and dial-up. Whichever funding is our major, there is an expectation that we will have a printer that will take all the different colours.

Downloading all those files constitutes, in the eyes of many coordinators, a 'downloading of costs' from funders and government who used to print out and physically mail documents that they now expect Neighbourhood Houses to print out on their own. In this case, technology is used to make existing power imbalances even worse, as well-resourced more powerful organizations reduce their costs through technology at the same time that they force less powerful community organizations to incur increased costs in ink, time, and paper.

We spend time printing it out and disseminating it. So we are part-timers and doing their [funders] work for them.

I think it's been surreptitious, this transfer of costs [making people print out e-mails].

There is no recognition of our increased printing costs. The tradeoffs of having things instantly outweighs the costs.

Estimates from some Neighbourhood Houses are that communications inefficiencies created by excessive e-mail and printing costs are costing more than an hour a day of internet and worker time and reams of paper a week.

In the focus group discussion we also learned that it was difficult for many people to access, download, and then open some files sent by departments (such as those in PDF format), due to the age of equipment or narrowband internet connection [see Section 4.5]. As one coordinator noted:

Funding stays the same but the IT expectations have grown.

And while some might argue that coordinators could save money by becoming more used to 'screen reading,' that is an impractical option for aging eyes using old low resolution monitors, for people who need to read documents on the tram or train, and for those who want to take things home with them. As the coordinators note:

It's not a paperless society--it's doubled it [paper use] at least.

Everyone would say they [computers] are indispensable. They haven't created less paper.

Another aspect of this problem is that those who send large attachments expect the recipient to be able to download them. That is not always possible for Neighbourhood Houses with slow dial-up connection. Older computers also sometimes freeze up with PDF files. In the survey, only six respondents listed access to broadband Internet, with the rest relying on dial-up service. And, as was learned in some of the site 
visits, at least two of the Houses relying on dial-up internet access were sharing that narrow bandwidth across multiple computers.

Often you have to print things out. It costs us more now because we have to print out so much. Sometimes it's hard to go to a website and there's six PDF files.

There's an expectation that you can get the attachment.

DHS wants online reporting, so we needed to install the program to do that. They have to do a client profile form. With community lunch, it needs its own kind of reporting process.

Another unintended consequence of IT in the community sector is the increased communication burden. The ease of sending e-mail has nearly eliminated information filtering. Consequently, Neighbourhood House coordinators receive mountains of unwanted, unfiltered, 'official' information by email. In the focus group, when we asked coordinators to remember the last time they had received truly useful information via e-mail, they couldn't even think of examples.

I am spending an hour and a half a day with e-mails.

People expect you to reply to an e-mail immediately.

I get 20-30 emails a day -- it mightn't sound like many, but they usually require work. I don't open a lot of them.

And there are risks to ignoring too much e-mail, useless as many of them appear to be:

A lot of communication with funders is through e-mail. There's a tendency to react to information too quickly on e-mail. You have to read it and think about it. You can miss out on something. If you don't manage it yourself, you could miss a deadline.

\section{Communication with councils and state government}

A main consequence of these sustainability gaps is that community organizations such as Neighbourhood Houses remain out of the communication loop with both their local and state government departments. Lacking websites to advertise themselves, lacking adequate technology and skills to develop databases that can be cutting edge and communication methods that can capture the attention and imagination of government, Neighbourhood Houses remain relatively invisible and ignored.

This final area of concern goes well outside of the area of information management and information technology, but is so much on the minds of the Neighbourhood House coordinators that it must be addressed. It is partly a communication issue, and may be addressable via the creative application of communication technologies. But it may primarily be a broader structural issue in how Neighbourhood Houses and councils relate to each other, and the structuring of council areas in relation to each other.

The problem is that each Neighbourhood House can be located in a different section of Council across Victoria...no cohesion, can't talk to each other across Councils.

People don't know what a Neighbourhood House is. No one places any importance on it. They don't know what community building is. That influences funding. We put pictures in the paper. People have gone in [to start projects] without Neighbourhood Houses and things don't work.

We used to have a strong relationship with council. Now it's deteriorated to the point where we only get e-mails from them. Council distanced themselves from service delivery. Now they've distanced themselves from service providers.

So bad is it in some places that Neighbourhood Houses are not even listed on council websites.

We would like local government to add Houses to their website.

I've asked council to put us on their website as a link. So people could click on a category of services and find us.

There are important costs to the lack of connection between Neighbourhood Houses and their local councils, both in terms of information flows from council to Neighbourhood Houses and in terms of information flows from Neighbourhood Houses to council. 
The rules change. You don't know which side of the fence you're on. One minute you're doing this and then all of a sudden they say you should be providing this other thing.

We should have a phone list of all the departments but they don't want to give them to us.

We get 2000 residents per week through our doors. They [council] are missing out on the information we get from that. We need council to write letters of support. It costs us because there is expertise in council that we can't tap. They've probably got access to data we don't have, and networks. There's a myriad of organisations and they could facilitate networking. They're quick to jump on youth issues, but community centres don't have prestige. We don't have social workers and counsellors on staff.

Not all the local councils exhibit such problems. In some local government areas, there are stronger relationships. But in general, this invisibility creates an environment where even more funding cuts are possible, creating a vicious cycle that can only be broken by an expansion of creative definitions for the deployment of technology and an effective organizing of agency that can attack and change the structural barriers to adequate technology resources.

\section{Strategies for Expanding Neighbourhood House Agency}

At the final planning meeting the Neighbourhood House representatives were asked to come up with recommendations for meeting these sustainability gaps, specifying what the strategy should be, who should be involved in the strategy, and where the resources should come from. Below is provided a brief summary of the recommendations developed in the research report. All of the recommendations show the tension between structure and agency in structuration theory, with the Neighbourhood House coordinators developing strategies explicitly directed at overcoming the structural challenges to expanded and improved ICT use among Neighbourhood House staff.

\section{Troubleshooting training}

There was strong interest in trouble shooting training so Neighbourhood House staff could diagnose and possibly fix technical problems before (expensive) paid help had to be brought in. To address the structural issue Coordinators recommended courses in the 10-20 hours range, accompanied by a manual designed for Neighbourhood House needs. These findings confirm the survey data, where half of the respondents indicated interest in information technology training, provided it was practical and time efficient. To overcome the structural barrier of lack of time, coordinators felt it would be desirable for the course to last 10-20 hours, be offered between terms (many Neighbourhood Houses are closed when school is not in session), with attending staff paid for their time and receiving a certificate upon successful completion. The trainings themselves may not require further resources, since there are funds available to the Neighbourhood House staff for professional development. However, resources may be required to develop new curriculum or adapt existing curriculum to the specific troubleshooting needs of Neighbourhood House staff.

\section{Good IT support}

The main strategy developed for finding affordable IT support was to organize a group tender for technical support. Given the large number of computers (potentially 500 or more) that such a contract would cover, a group tender could give the Neighbourhood Houses significant leverage in defining the scope, quality, and even cost of services. This could attack the structural barrier of the existing high cost of services. The Neighbourhood Houses are even willing to pay for high quality service, particularly if some kind of sliding scale fee structure could be developed. A remaining issue, again pointing to the importance of both the complexity of understanding the structure side of structuration theory, as well as the importance of situational definitions, is how to develop and manage the Neighbourhood House side of such contract negotiations, as this would require a large time commitment from at least some Neighbourhood House coordinators.

\section{Managing Information}

Because there are so many possible types of directories, there are also a number of different strategies. Using the situational definition strategy of structuration theory, one main strategy is to make sure that 
Neighbourhood Houses are aware of the existing directories. The development of other directories, have both structure and agency issues. A tutor directory will require a coordinated effort to get lists of tutors from Neighbourhood Houses and contact information from tutors, as well as funding to support the database development. To address these structuration issues, the Neighbourhood House coordinators agreed to send information about successful database projects they are already developing to the neighbourhood association newsletter and the Network West newsletter. As the discussion developed, this idea grew into creating a special section in each of those newsletters for Neighbourhood Houses to highlight their unique programs or services so others could learn about them, or to present a problem and ask whether any Neighbourhood House had developed a unique solution.

\section{Web development and Management}

The strategy chosen to address this issue is quite similar to the strategy for obtaining adequate IT support—organizing individual needs into a collective solution. Using the definitional strategy implied by structuration theory, most Neighbourhood Houses do not see a need for web pages to attract clients to their services, understanding that clients find out about them through word of mouth or print media such as flyers and newspaper ads. They do understand, however, that funders may look to see if a House has a website, and that other service providers may look for their website to make a referral. Many Neighbourhood Houses want a website that they don't have to design, and that is very easy to update. Such a site would be possible through the creation of a template on a single host, where a Neighbourhood House could fill in web-based forms with text information that would then be automatically compiled into a website. Creating a template could be accomplished by a single web designer in a university setting, or in Network West, in consultation with Neighbourhood Houses and funders to determine the categories of information needed. Given the concern expressed at the planning meeting about the need for Neighbourhood Houses to better 'brand' themselves, a central provider could offer the benefit of a common domain name and sub-domain naming of Neighbourhood Houses (eg. ww.networkwest.net/yourhouse/ or www.anhlc.asn.au/yourhouse), whatever the actual webhosting arrangements. Of course, some houses may choose to have their own domain name, as a number already do.

\section{Communication Standards}

Maximizing communication involves a three-facet strategy: reducing the size of electronic files, reducing the number of irrelevant communications, and reducing the cost of printing files. Here the strategy is to pit brute agency against brute structure, advocating for changes in the way that more powerful organizations communicate. Important again, however, is that much of the advocacy is focused on changing the current definition of electronic communication from one which has this as less expensive, to a definition where it may be less expensive for the sender but not for the recipient.

\section{Communication with councils and state government}

The costs of the lack of communication between local councils and Neighbourhood Houses is enormous in terms of referrals not made, services that are mis-targeted, and government programs that are misinformed. Because this is such a large multi-faceted governance issue, and since it goes well beyond questions of information management and information technology, the planning group found it difficult to make specific recommendations in this area. This again points to a definitional strategy informed by structuration theory. This research focused on the information and technology issues faced by Neighbourhood Houses. The challenge of communicating with local councils and state government goes beyond these matters. Consequently, one of the recommendations of the planning group was to conduct a study similar to this one, only focused on the relations between Neighbourhood Houses and government.

\section{CONCLUSION}

This project has become more than 'findings' on paper for a research report. Instead, as a social action project, it has become embedded in the (re-)structuration processes of private sphere-public sphereneighbourhood relations themselves, and consequently is helping to build Neighbourhood House agency.

The authors suggest that their engagement in the 'double hermeneutic' of engaging with the agencies has in fact provided these agencies with a circuit breaker, with a new means of changing value sets and political positions. It has provided them with new information with which to take action, and supports 
action that is meaningful and sustainable to them. Our conclusions outline how this research has in turn stimulated a change in understandings of internal relationships of power, communication, and resources by the Neighbourhood Houses themselves, and begun to engage, as a new stage in a community process, in impacting 'upward', external larger forces.

At the time of writing of this paper, processes are under way which include:

- Circulation of a detailed 'thick and rich' project report amongst Neighbourhood Houses for their consideration and comment. Their comments will help form and 'validate' the final report which will go into wider circulation for use in local planning networks.3

- Planning for a report launch by a senior minister of the state government. The political importance of such an event cannot be underestimated. Ideally, the launch event will be accompanied by the announcement of moves to develop new policies and funding arrangements as a partnership between the Houses and government. 4

- Quite separately to the previous point, the draft report has also been viewed by senior government advisers and a Parliamentary Secretary (the equivalent of a junior Minister) and it appears that the report has filled an information gap within various ministries. The human side of interaction with technology is little understood, and remarkably, the paper had demonstrated its own agency as a traditionally inert information object by contributing to a new enthusiasm for reengagement with the community in course of the development of ICT policy and programs. It has provided qualitative evidence that can be used against those who only understand hard numbers, and it will be used as part of high level strategic planning for the future development of community ICTs.

- There is recognition by government, on the basis of this research, that the sustainability of community ICTs depends upon effective support for the structural arrangements illuminated through our research. We also believe that this rush to action confirms the observation made in an earlier paper that there is a significant gap in government's understanding of the link between effective information and support services and new technology, the result of political and budget decisions made in the 1990s. Timely, grass-roots information is now valued.

- The report has also been well-received by academics in a number of faculties who are concerned about the development of an effective social mission in an era of the "enterprise university'. Community-based research as part of a social mission is not well-known in Australia, and it appears that the university may be prepared to back such activity more substantially in the future.

These outcomes represent the 'utilization stage' (Patton 1997) of the project, given the usefulness of engaged community based research as a way to create new forms of agency through affecting key structural principles for a variety of stakeholders, including direct clients and in this case, major sources of future funding and infrastructure support. These in turn are key to the sustainability of future Neighbourhood House activity with technology.

In addition, the project shows the utility of structuration theory in identifying both the structure and agency sides of the ICT sustainability gaps being experienced by Neighbourhood Houses. We also see, importantly, that just as the structure side of structuration theory is made up of both material and ideational elements, so is the agency side. In some cases, creating change involves engaging in action to change definitions of the role of ICTs in a community context. In other cases, it involves shifting resources. Ultimately, both are always involved, but with different emphases for different issues. 


\section{References}

Adams, P. C. (1995). "A Reconsideration of Personal Boundaries in Space-Time." Annals of the Association of American Geographers 85(2): 267-285.

Berger, P. L. and T. Luckmann (1966). The social construction of reality; a treatise in the sociology of knowledge. Garden City, N.Y.,, Doubleday.

Dear, M. J. (2000). The postmodern urban condition. Malden, Mass, Blackwell.

Department of Human Services (Victoria) (2002). Western Metropolitan Region Health and Social Wellbeing Profile. Melbourne, Department of Human Sevices (Victoria). (Accessed: 10 February, 2004, http://www.wil.infoxchange.net.au/library/contents/reports/older people WesternMetropolitanRe gionHealthandSocialWellbeingProfile0.pdf )

De Sanctis, G. and M. S. Poole (1994). "Capturing the complexity in advanced technology use: Adaptive Structuation Theory." Organization Science 5(2): 121-147.

Evans, S. M. and H. C. Boyte (1992). Free spaces : the sources of democratic change in America : with a new introduction. Chicago, University of Chicago Press.

Fetterman, D. (1994). "Empowerment Evaluation." Evaluation Practice 15(1).

Giddens, A. (1981). Agency, institution, and time-space analysis. Advances in social theory and methodology : toward an integration of micro- and macro-sociologies. K. D. Knorr-Cetina and A. V. Cicourel. Boston, Routledge \& Kegan Paul: 161-174.

--- (1984). The constitution of society : outline of the theory of structuration. Berkeley, University of California Press.

--- (1987). Social theory and modern sociology. Stanford, Calif., Stanford University Press.

Gould, N. (2003). The Caring Professions and Information Technology: In Search of a Theory. Information and communication technologies in the welfare services. E. Harlow and S. A. Webb. London ; Philadelphia, Pa., Jessica Kingsley Publishers: 29-48.

Gregson, N. (1989). On the (ir)relevance of structuration theory to empirical research. Social theory of modern societies : Anthony Giddens and his critics. D. Held and J. B. Thompson. Cambridge [England] ; New York, NY, USA, Cambridge University Press: 235-248.

Guba, E. G. and Y. S. Lincoln (1981). Effective evaluation. San Francisco, Jossey-Bass Publishers.

Hagerstrand, T. (1970). "What about people in regional science?" Papers and Proceedings of the Regional Science Association 24: 7-21.

Haraway, D. (2000). A Cyborg Manifesto: Science, technology, and socialist-Feminism in the late twentieth Century. London, Routledge.

Harvey, D. (1989). The Condition of Postmodernity, Blackwell.

Koerin, B. (2003). "The settlement house tradition: current trends and future concerns." Journal of Sociology \& Social Welfare 30(2): 53-69.

Kondrat, M. E. (1994). "Culutre and Power in Technology Transfer: Perspectives from a Critical Theory of Knowledge." Social Development Issues 16(3): 45-65.

Latour, B. (1994). Where are the Missing Masses? The Sociology of a Few Mundane Artifacts. Shaping technology/building society : studies in sociotechnical change. W. E. Bijker and J. Law. Cambridge, Mass., MIT Press: 224-258.

Law, J. (2001). Networks, Relations,Cyborgs: on the Social Study of Technology (draft), Centre for Science Studies and the Department of Sociology, Lancaster University. (Accessed: 6 June, 2003, http://www.comp.lancs.ac.uk/sociology/soc042jl.html ) 
Nyden, P. W. (1997). Building community : social science in action. Thousand Oaks, Calif., Pine Forge Press.

Orlikowski, W. J. (1992). "The Duality of Technology: Rethinking the Concept of Technology in Organizations." Organization Science, 3, 3, 1992: 3(3): 398-427.

--- (1999). Technologies-in-practice : an enacted lens for studying technology in organizations. Cambridge, MA, Sloan School of Management Massachusetts Institute of Technology.

--- (2000). "Using technology and constituting structures: A practice lens for studying technology in organizations." Organization Science 11(Jul/Aug): 404-428.

--- (2002). "Knowing in practice: Enacting a collective capability in distributed organizing." Organization Science 13(May/Jun): 249-273, 25 pages.

Patton, M. Q. (1997). Utilization-focussed Evaluation. Thousand Oaks, Sage.

Poole, D. L. and I. C. Colby (2002). "Do public neighborhood centers have the capacity to be instruments of change in human services?" Social Work 47(2): 142-152.

Poole, M. S., Seibold, D. R., \& McPhee, R. D. (1986). A structurational approach to theory-building in group decision-making research. In R. Y. Hirokawa \& M. S. Poole (Eds.), Communication and group decision making (pp. 2437-264). Beverly Hills: Sage.

Reed, M. I. (1997). "In praise of duality and dualism: Rethinking agency and structure in organizational analysis." Organization Studies 18: 21-42.

Rose, J. (1999). Towards a structurational theory of IS, theory development and case study illustrations. Proceedings of the 7th European Conference on Information Systems, Copenhagen.

Strand, K., S. Marullo, N. Nick Cutforth, R. Stoecker and P. Donohue (2003). Community-Based Research and Higher Education: Principles and Practices. San Francisco, CA, Jossey-Bass.

Turner, V. W. (1974). Dramas, fields, and metaphors; symbolic action in human society. Ithaca [N.Y.], Cornell University Press.

Webb, S. A. (2003). Technologies of Care. Information and communication technologies in the welfare services. E. Harlow and S. A. Webb. London; Philadelphia, Pa., Jessica Kingsley Publishers: 223238.

Weber, M., E. Shils and H. A. Finch (1949). The methodology of the social sciences. New York, The Free Press.

Weick, K. (1990). Technology as Eviquoque: Sensemaking in New Technologies. Technology and organizations. P. S. Goodman and L. Sproull. San Francisco, Jossey-Bass: xxi, 281.

Zukin, S. (1991). Landscapes of power : from Detroit to Disney World. Berkeley, University of California Press.

1 Adaptive structuration theory's small group, explanatory focus tends to underplay the influence of larger forces which influence the context of micro-level interrelationships. This can lead to a bracketing of critical questions about ultimate causal, structural relationships. Reed refers to this as a single-level social ontology in which agency and structure are 'rendered down to localised social practices bereft of any institutional underpinnings or contextualization, insightful as it may be at the micro-level of interaction between players' (Reed, 1997: 25).

2 Tip: always carry around a 30' extension and an extra conference phone.

3 We anticipate that the final version of the report will be made available on line shortly. 
4 One remarkable aside came from one of our high-level contacts. 'In this state there are not two, but three political parties: Liberal (the Conservatives), Labour, and Treasury'. The Thatcherite ideology of public service is the most difficult to change. 